\title{
Optimization of glutathione production in batch and fed-batch cultures by the wild-type and recombinant strains of the methylotrophic yeast Hansenula polymorpha DL-1
}

Vira M Ubiyvovk ${ }^{1,2}$, Vladimir M Ananin ${ }^{2}$, Alexander Y Malyshev ${ }^{1}$, Hyun Ah Kang ${ }^{2,3}$, Andriy A Sibirny ${ }^{1,4^{*}}$

\begin{abstract}
Background: Tripeptide glutathione (gamma-glutamyl-L-cysteinyl-glycine) is the most abundant non-protein thiol that protects cells from metabolic and oxidative stresses and is widely used as medicine, food additives and in cosmetic industry. The methylotrophic yeast Hansenula polymorpha is regarded as a rich source of glutathione due to the role of this thiol in detoxifications of key intermediates of methanol metabolism. Cellular and extracellular glutathione production of $\mathrm{H}$. polymorpha DL-1 in the wild type and recombinant strains which overexpress genes of glutathione biosynthesis (GSH2) and its precursor cysteine (MET4) was studied.
\end{abstract}

Results: Glutathione producing capacity of H. polymorpha DL-1 depending on parameters of cultivation (dissolved oxygen tension, $\mathrm{pH}$, stirrer speed), carbon substrate (glucose, methanol) and type of overexpressed genes of glutathione and its precursor biosynthesis during batch and fed-batch fermentations were studied. Under optimized conditions of glucose fed-batch cultivation, the glutathione productivity of the engineered strains was increased from $\sim 900$ up to $\sim 2300 \mathrm{mg}$ of Total Intracellular Glutathione (TIG) or GSH+GSSG in, per liter of culture medium. Meantime, methanol fed-batch cultivation of one of the recombinant strains allowed achieving the extracellular glutathione productivity up to $250 \mathrm{mg}$ of Total Extracellular Glutathione (TEG) or GSH+GSSG ex $_{\text {, }}$ per liter of the culture medium.

Conclusions: H. polymorpha is an competitive glutathione producer as compared to other known yeast and bacteria strains (Saccharomyces cerevisiae, Candida utilis, Escherichia coli, Lactococcus lactis etc.) with good perspectives for further improvement especially for production of extracellular form of glutathione.

\section{Background}

Tripeptide glutathione ( $\gamma$-glutamyl-L-cysteinyl-glycine) is the most abundant non-protein thiol compound of the most living organisms that protects cells from nutritional, environmental and oxidative stresses [1]. More than $90 \%$ of microbial, plant and mammalian cell glutathione is present in the reduced form, designated as GSH [2]. Both thiol GSH and disulfide form of oxidized glutathione, GSSG, are widely used in medicine and cosmetic industry, as well as food additives $[3,4]$. As an active ingredient of food, drugs and cosmetic products,

\footnotetext{
* Correspondence: sibirny@cellbiol.lviv.ua

${ }^{1}$ Institute of Cell Biology NAS of Ukraine, Drahomanov Street, 14/16, Lviv, 79005 Ukraine

Full list of author information is available at the end of the article
}

GSH could alleviate harmful oxidative processes, scavenge toxic compounds at different kinds of human intoxications and strengthen whitening, skin repair antiaging effect. Oxidized form of glutathione, GSSG, could be used as cryoprotector, immunomodulator etc. $[5,6]$. Thus, production of glutathione has great commercial importance.

In spite of the expanding commercial demand for glutathione, its application is restricted due to the high production costs. GSH and GSSG could be produced by enzymatic methods (expansive and unprofitable) and by fermentation using natural or engineering microorganisms (yeasts Saccharomyces cerevisiae and Candida utilis, bacteria Escherichia coli and Lactococcus lactis etc.) [3,4]. As a rule, microbial GSH overproduction is limited by 
mechanisms of feedback inhibition by GSH of the activity of the first and rate-limiting enzyme of GSH biosynthesis, gamma-glutamylcysteine synthetase (GCS) as well as GSH-exerted repression of the structural genes coding for GCS [2-4]. Thus, the search and/or construction of new and efficient glutathione producers as well as optimization of conditions of glutathione biosynthesis would assist in its bringing to market for the improvement of quality of food, cosmetic and pharmaceutical products.

During the last decades the methylotrophic yeast Hansenula polymorpha from three genetic lines, DL-1, CBS4732, NCYC495, have gained increasing interest, both for basic research and biotechnological applications, which include studying the mechanisms of thermotolerance, peroxisome homeostasis, production of numerous heterologous proteins and high-temperature alcoholic fermentation [7-12]. The industrial relevance of $H$. polymorpha is mostly explained by several technologically interesting features. This yeast grows to very high cell densities in bioreactors, possesses strong regulatory and constitutive promoters and consequently gives high product yields. Like S. cerevisiae, H. polymorpha is characterized by simple cultivation mode in inexpensive growth media, well established genetic tools and experience on industrial cultivation and scaling-up. $H$. polymorpha is considered as GRAS organism, it does not harbour pyrogens, pathogens or viral inclusions. In addition, completed genome sequencing $[13,14]$, established proteome and transcriptome databases $[15,16]$ makes $H$. polymorpha suitable organism for metabolic engineering in order to modify and improve particular biosynthetic pathways [10-12].

H. polymorpha is regarded as a rich source of glutathione, due to the role of this tripeptide in detoxifications of key intermediates of methanol metabolism, formaldehyde, as well as hydrogen peroxide and alkyl hydroperoxides, which are accumulated during methylotrophic growth [17-19].

In our previous study, we estimated physiological role of some $H$. polymorpha genes involved in GSH homeostasis: $H$. polymorpha GSH2 gene, $H p G S H 2$, a homologue of S. cerevisiae GSH1 gene coding for GCS, [20-22]; $H$. polymorpha GGT1 gene, homologue of S. cerevisiae CIS2/ECM38 gene encoding for gamma-glutamyltranspeptidase [23]; H. polymorpha MET4 gene, HpMET4, similarly to S. cerevisiae MET4 gene involved in global sulfur regulation $[24,25]$. We identified GSH as the sole cadmium ion chelator in $H$. polymorpha [26]. Meantime, until now, biotechnological potential of $H$. polymorpha in production of glutathione was not elucidated. In the present study, we studied glutathione producing capacity of $H$. polymorpha DL-1 wild-type strain and several recombinant strains with overexpression of the first gene in glutathione synthesis $\mathrm{HpGSH2}$, depending on parameters of cultivation (dissolved oxygen tension, $\mathrm{pH}$, stirrer speed), carbon substrate (glucose, methanol) and type of overexpressed genes of GSH biosynthesis in recombinant strains during batch and fed-batch fermentations. Under optimized conditions of glucose fedbatch cultivation, engineered strains accumulated more than $2250 \mathrm{mg}$ of Total Intracellular Glutathione (TIG) or $G S H+G S S G_{\text {in }}$, per liter of culture medium, which slightly exceeds the known before maximal glutathione production in S. cerevisiae of $2020 \mathrm{mg} / \mathrm{L}$ (however, last number was obtained with addition of amino acids to cultural medium, which increases the costs of the aimed product) [27]. One of constructed by us $H$. polymorpha recombinant strains was promising producer of the extracellular glutathione in methanol medium as accumulated 5-times higher titer of Total Extracellular Glutathione (TEG) or GSH+GSSG ${ }_{\mathrm{ex}}$, as compared to best level achieved before for yeasts [3].

\section{Results and Discussion}

Growth and glutathione production of $H$. polymorpha

DL-1 wild-type strain cultivated in fermenter batch cultures with glucose at different modes of $\mathrm{pH}$ control and aeration

To choose the most glutathione productive strain for further work, we compared intra- and extracellular GSH +GSSG levels (hereinafter - GSH+GSSG in or TIG and GSH+GSSG ${ }_{\text {ex }}$ or TEG, respectively) in H. polymorpha wild-type strains DL-1L, CBS4732L and NCYC495L from three genetic lines (Tables 1,2) [28] using simple enzyme assay that does not differentiate reduced and oxidized forms of glutathione, as both have biotechnological application.

So, the strains of $H$. polymorpha derived from the genetic line DL-1 with the highest levels of

\section{Table 1 Strains of $H$. polymorpha used in the} present study

\begin{tabular}{|c|c|c|}
\hline Designation & $\begin{array}{l}\text { Genotype or } \\
\text { relevant features }\end{array}$ & Reference or source \\
\hline \multicolumn{3}{|c|}{ Wild type strains } \\
\hline NCYC495L & leut-1 & Laboratory collection \\
\hline CBS4732L (A16) & leu2 & Laboratory collection \\
\hline$D L-1 L$ & leu2 & Laboratory collection \\
\hline $\mathrm{DL}-1$ & $\begin{array}{l}\text { leu2::LEU2 (plasmid } \\
\text { vector pGLG61) }\end{array}$ & This study \\
\hline \multicolumn{3}{|l|}{$\begin{array}{l}\text { Recombinant } \\
\text { strains of DL-1 }\end{array}$} \\
\hline mcGSH2 & $\begin{array}{l}\text { leu2:: LEU2::mcGSH2 } \\
\text { (pGLG61-HpGSH2) }\end{array}$ & This study \\
\hline MOXp-GSH2 & $\begin{array}{l}\text { leu2::LEU2::MOXp-GSH2 } \\
\text { (pGLG61- HpMOXp::HpGSH2) }\end{array}$ & This study \\
\hline mCMET4 & $\begin{array}{l}\text { leu2:: LEU2::mcMET4 } \\
\text { (pGLG61-HpMET4) }\end{array}$ & Laboratory collection \\
\hline
\end{tabular}


Table 2 Maximal biomass and glutathione (TIG and TEG) production of $\boldsymbol{H}$. polymorpha strains at different conditions of fermentation

\begin{tabular}{|c|c|c|c|c|c|c|c|c|c|}
\hline \multirow[t]{2}{*}{ Strains } & \multicolumn{3}{|c|}{ Conditions of fermentation } & \multicolumn{4}{|c|}{ TIG } & \multirow{2}{*}{$\begin{array}{c}\text { TEG } \\
\mathrm{mg} / \mathrm{L}\end{array}$} & \multirow{2}{*}{$\begin{array}{c}\text { Biomass } \\
\text { Dry cells } \mathrm{g} \\
\mathrm{L}\end{array}$} \\
\hline & & & & $\begin{array}{c}\mathrm{nmol} / \mathrm{mg} \\
\text { protein }\end{array}$ & $\begin{array}{c}\% \mathrm{w} / \\
\mathrm{w}\end{array}$ & $\begin{array}{l}\mathrm{mg} / \mathrm{g} \text { of dry } \\
\text { cells }\end{array}$ & $\mathrm{mg} / \mathrm{L}$ & & \\
\hline $\begin{array}{l}\text { Wild-types } \\
\text { NCYC495L }\end{array}$ & & & & $177 \pm 1.5$ & 0.6 & 6 & $20 \pm 0.15$ & $1 \pm 0.05$ & $3.2 \pm 0.26$ \\
\hline CBS 4732L & Shake- & Glucose & $\begin{array}{l}200 \mathrm{rpm} \\
\text { (w/o pH } \\
\text { control) }\end{array}$ & $380 \pm 3.2$ & 0.9 & 9 & $24 \pm 0.19$ & $1 \pm 0.06$ & $2.8 \pm 0.19$ \\
\hline \multirow[t]{3}{*}{$\mathrm{DL}-1 \mathrm{~L}$} & flask & & & $481 \pm 3.9$ & 1.0 & 10 & $27 \pm 0.21$ & $2 \pm 0.09$ & $2.8 \pm 0.18$ \\
\hline & & & $\begin{array}{c}200 \mathrm{rpm} \\
\text { (pH control 5.2) }\end{array}$ & $161 \pm 1.49$ & 0.5 & 5 & $20 \pm 1.4$ & $2 \pm 0.19$ & $4.0 \pm 0.36$ \\
\hline & Batch & & $\begin{array}{c}600 \mathrm{rpm} \\
(-"-" \text { - " -" - ) } \\
\end{array}$ & $50 \pm 0.45$ & 0.3 & 3 & $17 \pm 1.19$ & $12 \pm 1.10$ & $6.9 \pm 0.42$ \\
\hline \multirow[t]{2}{*}{ Wild type DL-1 } & Fermenter & Glucose & $\begin{array}{c}200 \text { rpm } \\
\text { (w/o pH } \\
\text { control) }\end{array}$ & $373 \pm 3.12$ & 1.1 & 11 & $69 \pm 6.49$ & $2 \pm 0.20$ & $6.1 \pm 0.39$ \\
\hline & & & $\begin{array}{c}800 \mathrm{rpm} \\
(-"-" \text { - " - - - ) } \\
\end{array}$ & $269 \pm 2.11$ & 0.6 & 6 & $49 \pm 4.45$ & $17 \pm 1.59$ & $7.7 \pm 0.45$ \\
\hline Wild type DL-1 & & Methanol & DO-stat 60\% & 136 & 0.8 & 8 & 676 & 37 & 90 \\
\hline Wild type DL-1 & & Glucose & DO- stat 60\% & 183 & 1.2 & 12 & 518 & 22 & 44 \\
\hline Wild type DL-1 & & Glucose & DO- stat 30\% & 315 & 1.3 & 13 & 910 & 4 & 72 \\
\hline mCMET4 & Fed-batch & Glucose & $\left(-"{ }^{\prime \prime}-"{ }^{\prime \prime}-"\right)$ & 318 & 1.6 & 16 & 1318 & 6 & 82 \\
\hline mcGSH2 & fermenter & Glucose & $\left(-"{ }^{\prime \prime}-"{ }^{\prime \prime} "\right)$ & 755 & 2.0 & 20 & 1532 & 1 & 77 \\
\hline MOXp-GSH2 & & Glucose & $\left(-"{ }^{\prime \prime} "-"{ }^{\prime \prime}\right)$ & 409 & 3.1 & 31 & 2257 & 13 & 72 \\
\hline MOXp-GSH2 & & Methanol & DO-stat 60\% & 243 & 2.1 & 21 & 1053 & 250 & 55 \\
\hline
\end{tabular}

GSH+GSSG in $(\mathrm{TIG})$ as well as $\mathrm{GSH}+\mathrm{GSSG}_{\mathrm{ex}}(\mathrm{TEG})$ were used for the next studies (Table 2).

The growth and total intracellular glutathione (TIG) content in $H$. polymorpha DL-1 wild-type strain during batch cultivation in fermenter was studied depending on growth parameters, $\mathrm{pH}$ and aeration (Figure 1). It was shown that this yeast produced more TIG during cultivation in glucose minimal medium under conditions of spontaneous $\mathrm{pH}$ acidification from $\mathrm{pH} 5.0$ to 2.5 as compared to that at mode during $\mathrm{pH} 5.2$ maintenance using an active pH control (Figure 1 - B, C, D; Table 2). It was demonstrated also that TIG was higher at low stirrer speed $(200 \mathrm{rpm})$ than under intensive aeration (600-800 rpm), independently of $\mathrm{pH}$ control regime (Figure 1 - B, C, D; Table 2). After $8 \mathrm{~h}$ of cultivation at $200 \mathrm{rpm}$, DO parameter dropped from $94-98 \%$ to $3-4 \%$ and was maintained at the latter level till the end of process, in contrast to cultivation at 600-800 rpm, when the excess of oxygen was provided to culture during all process (Figure 1E). Maximal cell biomass concentration was higher under conditions of high saturation with oxygen (shake agitation at 600-800 rpm) as compared to low aeration (200 rpm), independently on the mode of $\mathrm{pH}$ control (Figure 1A; Table 2).

It should be noted that the level of Total Extracellular Glutathione (TEG) GSH+GSSG ex relative to that of TIG $\left(G S H+G S S G_{\text {in }}\right)$ became significant in the cases of high agitation (600-800 rpm), independently on $\mathrm{pH}$ control mode (Figure 1 - C, D). To explain these results, one may suggest that supply cells with more oxygen at 600-800 rpm provided more optimal growth conditions as we observed increase in biomass concentration. Oxygen-limited yeast cells cultivated at low stirrer speed, $200 \mathrm{rpm}$, most probably are suffered from metabolic stress induced by oxygen limitation. This stress could reduce growth activity and turned on cellular protection mechanisms including glutathione biosynthesis [29]. The reasons of $\mathrm{GSH}+\mathrm{GSSG}_{\mathrm{ex}}$ changes depending on oxygen level remain obscure.

\section{Biomass and glutathione production by $H$. polymorpha DL-1 wild type strain under fed-batch fermentation in glucose minimal medium under different modes of aeration}

We compared biomass and glutathione producing capacities of $H$. polymorpha DL-1 wild-type strain under different dissolved oxygen (DO) saturation conditions, DO-stat $30 \%$ and DO-stat $60 \%$, provided in fed-batch cultures in glucose minimal medium (see Materials and Methods) (Figure 1D). Similarly to batch culture cultivation, we observed elevated level ( 2-3 times) of TIG content during fermentation at low oxygen supply, DOstat $30 \%$, as compared to those at DO-stat $60 \%$ (Figure 2 - B, C). Unexpectedly, enhanced oxygen supply (DO- 

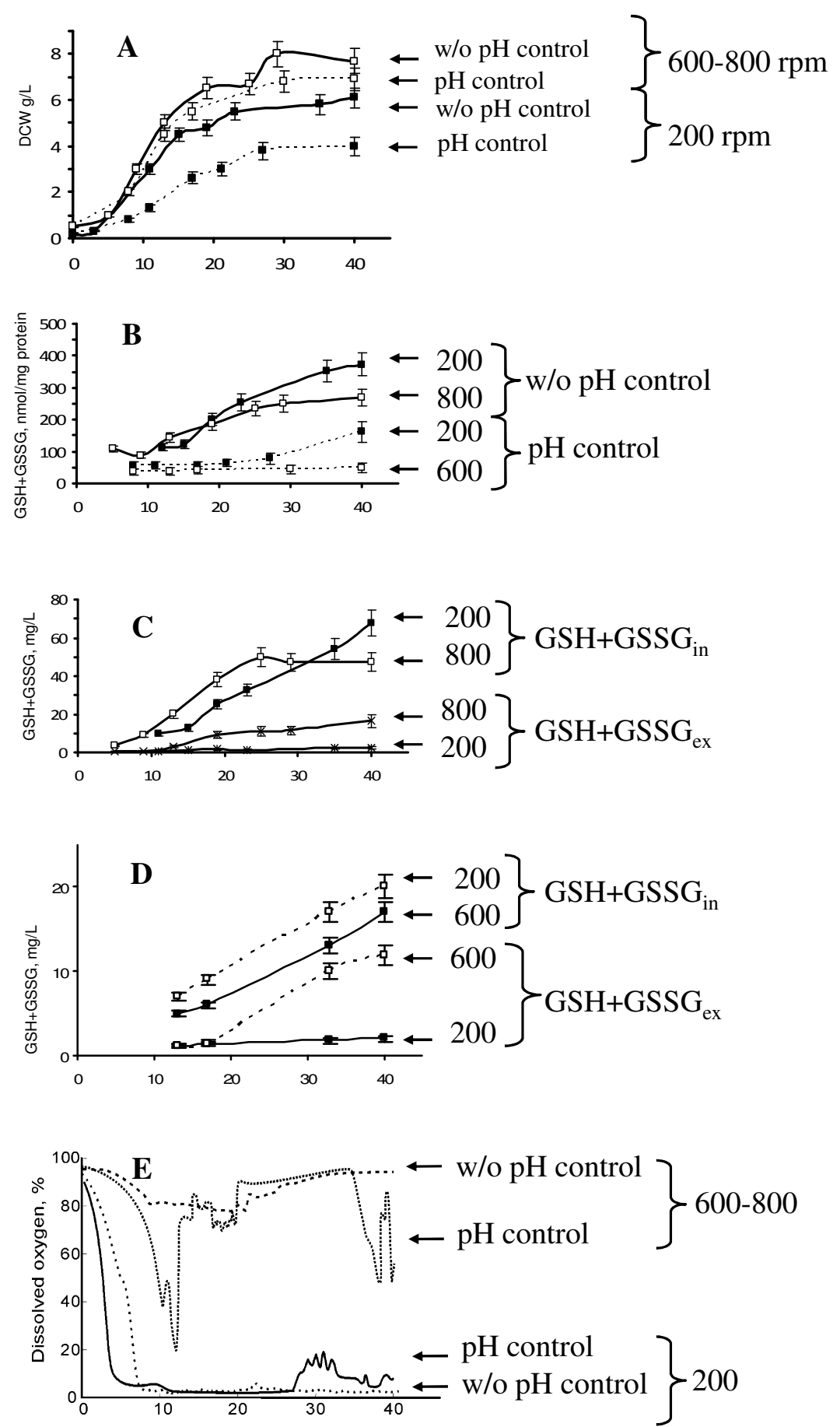

Time, h

Figure 1 Growth and glutathione accumulation of $\boldsymbol{H}$. polymorpha DL-1 at fermenter batch cultivations. A - Dry cell weight (DCW); B, C, D - TIG $\left(G_{S H}+G S S G_{i n}\right)$ and TEG (GSH+GSSG $)_{\text {ex }}$ concentrations, expressed in nmol/mg protein (B) and in mg/L culture medium (C, D). H.

polymorpha DL-1 wild type strain was cultivated with glucose at different modes of $\mathrm{pH}$ control and aeration: fermentation with $\mathrm{pH}$ control at 5.2 (pH control), fermentation without pH control (w/o pH control), aeration at stirrer speed of $200 \mathrm{rpm}$ (200) and at $600 \mathrm{rpm}$ (600); data for TIG and TEG accumulation at different aeration without $\mathrm{pH}$ control and with $\mathrm{pH}$ control (C and $\mathbf{D}$, respectively); $\mathbf{E}$ - data of dissolved oxygen tension in culture media at different mode of aeration and $\mathrm{pH}$ control. Values shown are the means of three independent determinations. 

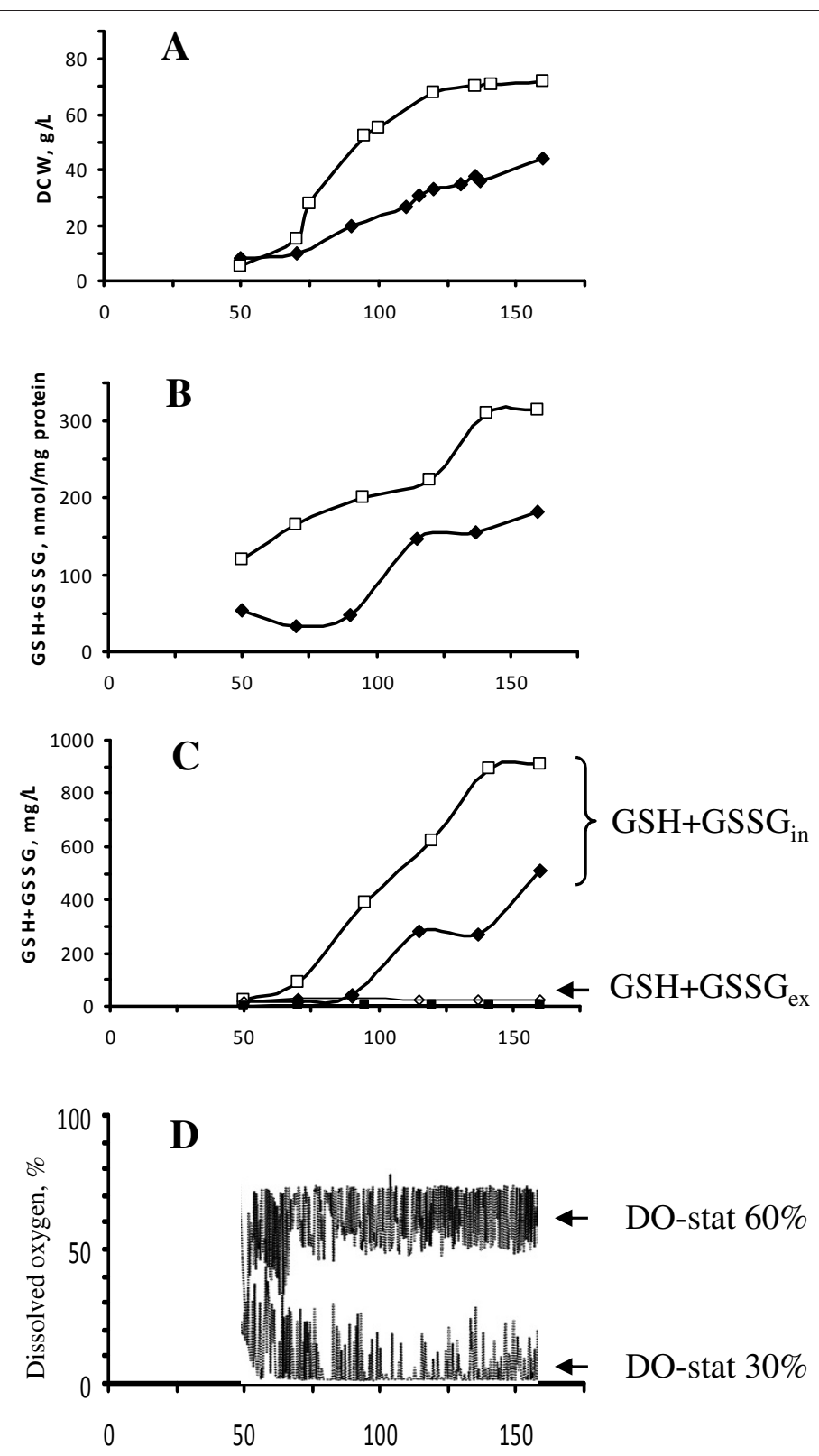

Time, h

Figure 2 Growth and glutathione accumulation of $\boldsymbol{H}$. polymorpha DL-1 at fermenter fed-batch cultivation. A - Dry cell weight (DCW); B, C - TIG (GSH+GSSG ${ }_{i n}$ ) and TEG (GSH+GSSG ${ }_{\text {ex }}$ ) concentrations, expressed in nmol/mg protein (B) and in mg/L culture medium (C) of $H$. polymorpha DL-1 wild type strain cultivated under different dissolved oxygen tension (DO) set point control of glucose feeding: DO-stat 30\% (open square) and DO-stat 60\% (filled rhombus). D - data of dissolved oxygen tension in culture media at different mode of aeration. Values shown are the means of two independent determinations.

stat $60 \%)$ caused reduction of biomass yield of fed-batch cultivated wild-type cells in glucose-containing minimal medium (Figure 2A). We hypothesize that yeast cells supplied with enhanced oxygen suffered from excess of reactive oxygen species. It is known that the lasts could suppress growth activity and trapped accessible for measurement glutathione in the reactions of
S-glutathiolation of protein and conjugation with product of lipid peroxidation [30,31].

In the meantime, intensification of oxygen supply led to slight increase in TEG level (Table 2). The maximal concentration of TEG by the wild-type cells was negligible and comprised 4-22 mg/L as compared to maximal TIG content $\sim 900 \mathrm{mg} / \mathrm{L}$ achieved under conditions of 
low oxygen supply, DO-stat 30\% under fed-batch conditions for the same cells (Figure 2C; Table 2).

\section{Biomass and glutathione production by $H$. polymorpha DL-1 recombinant strains at fed-batch fermentation in glucose minimal medium}

We hypothesized that accumulation of elevated TIG level can be achieved in recombinant $H$. polymorpha strains which overexpress this tripeptide. Consequently, we have studied TIG production in several $H$. polymorpha recombinant strains which harbored the additional copies of $H p G S H 2$ gene. As it was revealed earlier, H. polymorpha GSH2 gene, HpGSH2, a homologue of S. cerevisiae GSH1 gene, encoding GCS, the first enzyme of GSH biosynthesis, is essential for yeast growth and stress reply $[20,21]$. One of the obtained in the present study recombinant strains designated as $m c G S H 2$ transformant possessed 2-3 copies of HpGSH2 expression cassette under native $H$. polymorpha GSH2 promoter (Figure 3). Another recombinant strain, named as MOXp-GSH2 transformant, acquired HpGSH2 expression cassette under control of the strong promoter of $H$. polymorpha alcohol oxidase $M O X$ gene. The $M O X$ promoter is known to be regulated in H. polymorpha by mechanisms of glucose repression-derepression and methanol induction [32]. We also studied transformant named as mcMET4 that obtained 2-3 additional copies of $H$. polymorpha MET4 gene (Figure 3), putative

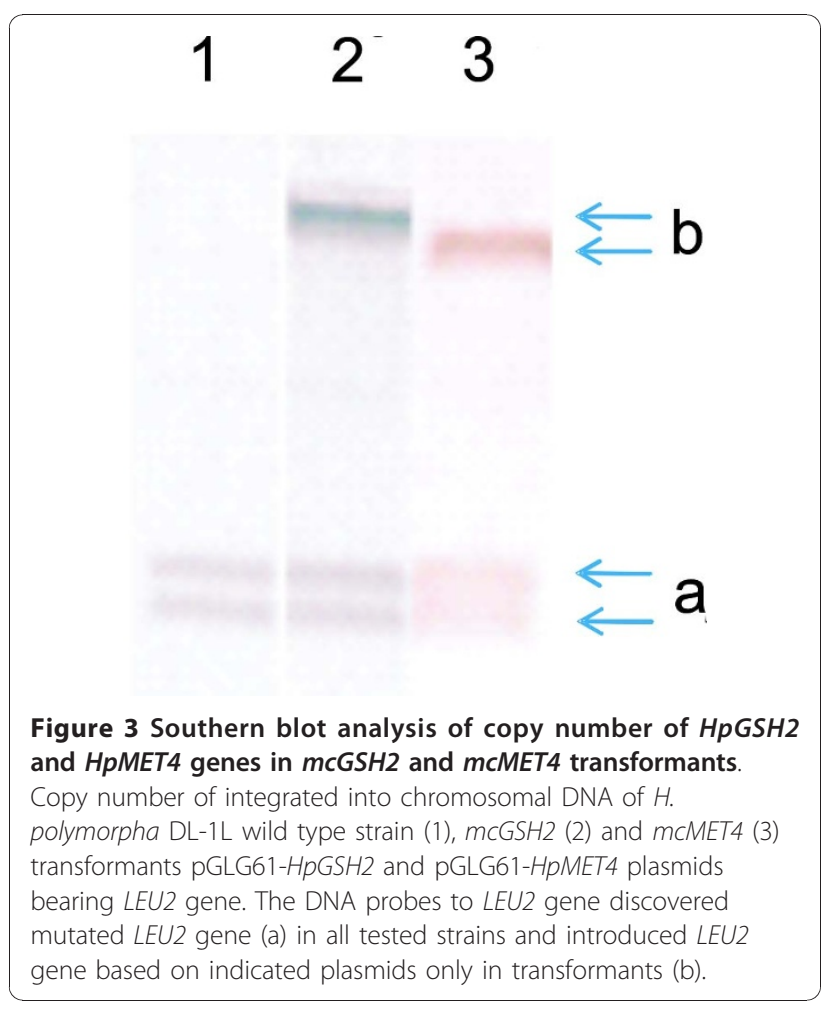

homologue of S. cerevisiae MET4 gene involved in biosynthesis of GSH and its precursor, cysteine [24,25].

All indicated strains displayed the growth kinetics under fed-batch fermentation process at DO-stat 30\% in glucose minimal medium very similar to that of the wild-type strain, except slightly elevated maximal biomass concentration of $m c G S H 2$ and mcMET4 recombinant strains (by $8 \%$ and $13 \%$, respectively) (Figure $4 \mathrm{~A}$ ). If to express glutathione/protein ratio, the highest TIG concentration was found in $m c G S H 2$ transformants (Figure 4B). However, when we compared TIG concentrations as the mass percentage of total glutathione to the total dry cell weight (\%) or per Liter of culture medium $(\mathrm{mg} / \mathrm{L})$, the best TIG producer appeared to be the MOXp-GSH2 recombinant strain (Figure 4C; Table 2 ). We explained such data discrepancy by differences in protein content of the compared strains. The strains in decreasing order of TIG concentrations (\%) can be ranged in the following order: MOXp-GSH2 - 3.1\%, mcGSH2 - 2.0\%; mcMET4- $1.57 \%$; wild type $-1.25 \%$. The same order of strains was if to express TIG concentration in mg/L: MOXp-GSH2 - $2257 \mathrm{mg} / \mathrm{L}$; mcGSH2 - $1532 \mathrm{mg} / \mathrm{L} ;$ mcMET4- $1318 \mathrm{mg} / \mathrm{L}$; wild type $-910 \mathrm{mg} / \mathrm{L}$.

Thus, introduction of additional copies of putative HpMET4 gene into the genome of recipient strain 1.5 -fold increased the TIG level in mcMET4 transformant, probably, due to activation of biosynthesis of GSH precursor, cysteine.

mcGSH2 transformant displayed only 1.7 times enhanced TIG level as compared to that in the wildtype strain in spite of obtaining of 3-4 copies of HpGSH2 gene. We have found the HpGSH2 gene overexpression in $m c G S H 2$ transformant cultivated in medium without any carbon substrate (Figure 4). Such conditions resembled fed-batch cultivation where glucose concentrations was maintained at the level lower than $0.01-0.05 \%$. It seems that GSH excess restricted glutathione overproduction in our recombinant strains by mechanism of feedback inhibition of GCS activity.

Nevertheless we did not confirm regulated from $M O X$ promoter expression of $\mathrm{HpGSH} 2$ gene (data of RT-PCR) in the recombinant strain that obtained such construct. Mode of expression of $\mathrm{HpGSH} 2$ gene from $M O X$ promoter was the same as in the wild-type strain (Figure 5). So, 2.5 times improvement of glutathione production in MOXp-GSH2 transformant could be explained by insertion of cassette into some regulatory locus important for GSH biosynthesis or under unknown promoter.

Concentration of the TEG $\left(\mathrm{GSH}+\mathrm{GSSH}_{\mathrm{ex}}\right)$ by the studied wild type and recombinant strains was negligible: 2-13 $\mathrm{mg} / \mathrm{L}$ as compared to their TIG level comprising of 910-2257 mg/L (Figure 4C; Table 2). 

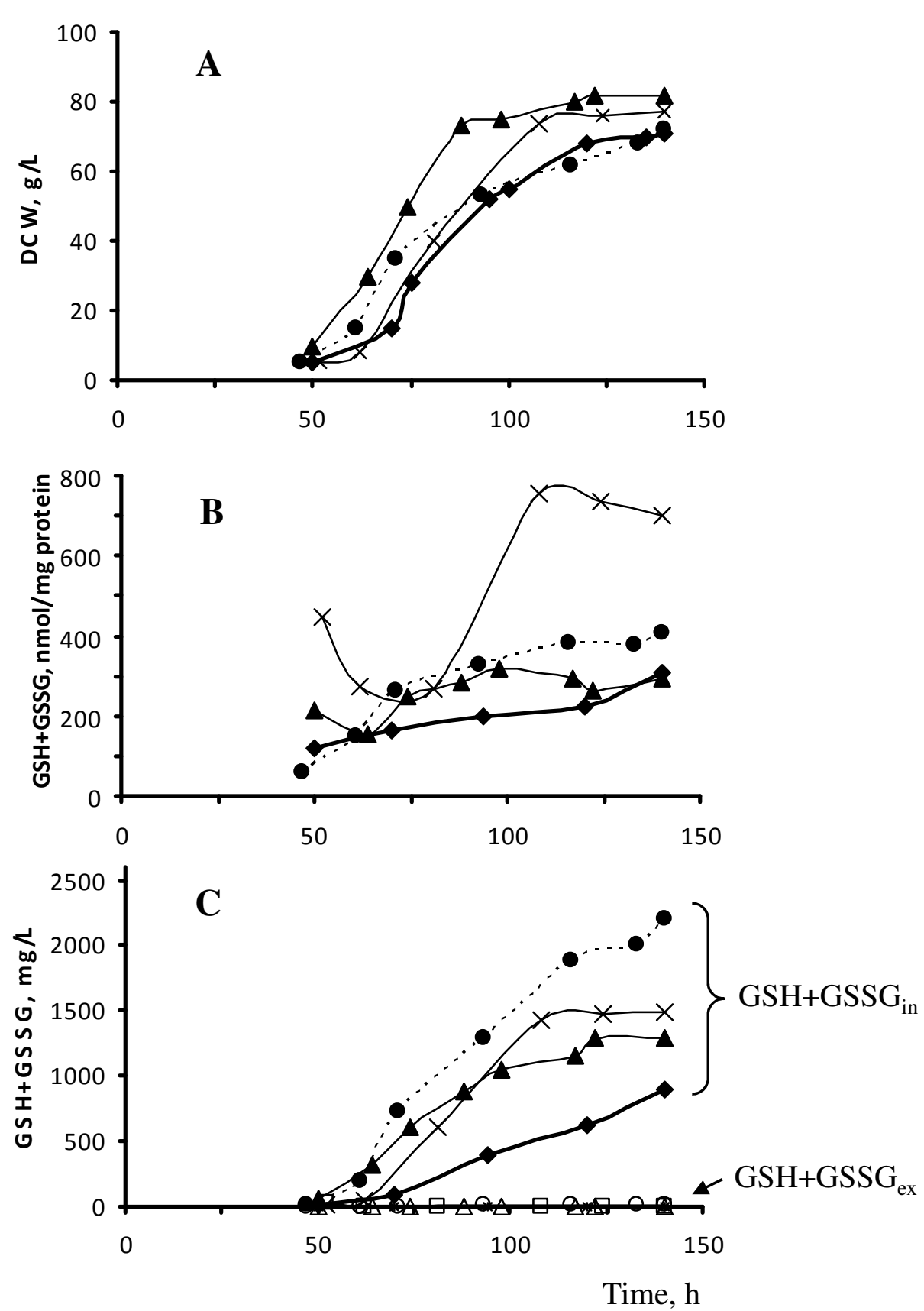

Figure 4 Growth and glutathione accumulation of $H$. polymorpha DL-1 recombinant strains at glucose-feeding fermenter cultivation. A

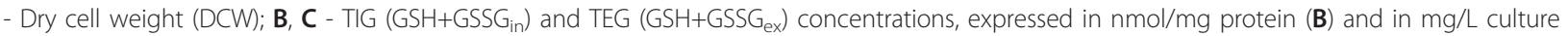
medium (C) of H. polymorpha DL-1 wild type (rhombus) and recombinant strains: MOXp-GSH2 (cycle), mcGSH2 (cross), mcMET4 (triangle) at fedbatch cultivation in glucose minimal medium under condition of DO-stat 30\%. TEG concentration is indicated with open symbols (C). Values shown are the means of two independent determinations.

Biomass and glutathione production by $H$. polymorpha DL-1 wild type and MOXp-GSH2 recombinant strains during fed-batch fermentation in methanol minimal medium HpGSH 2 transcript analysis revealed methanol-dependent induction of this gene expression in all studied strains compared to that of glucose incubated yeast cells
(Figure 5). Nevertheless, we did not observe strong increase of TIG concentration in methanol-feeding wild type cells (DO-stat 60\%) relative to that of glucosefeeding cells (DO-stat 60\%) (Table 2). Methanol fed-batch fermentations study was carried out only under DO-stat $60 \%$ that provides the highest biomass 


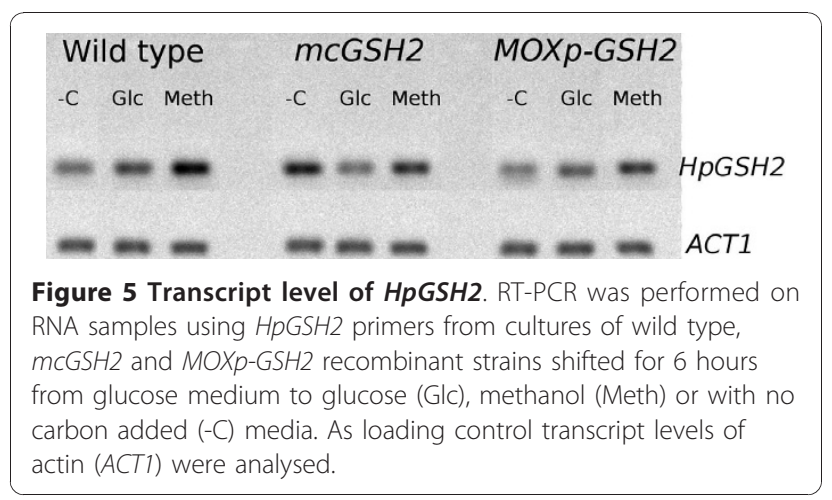

yield of $H$. polymorpha compared to DO-stat 30\% $[33,34]$. Moderate TIG concentrations (expressed in $\mathrm{nmol} / \mathrm{mg}$ protein or \%) during methanol feeding process was partially compensated by high maximal concentration of biomass $(90 \mathrm{~g} / \mathrm{l})$. We suggested that application of oxygen control during methanol feeding under fedbatch cultivation prevents the over-feeding of methanol and overaccumulation of toxic intermediates that could additionaly induce GSH biosynthesis [18].

Studied here MOXp-GSH2 recombinant strain was characterized by normal growth in glucose fed-batch cultures with minimal medium (Figure 4A) but
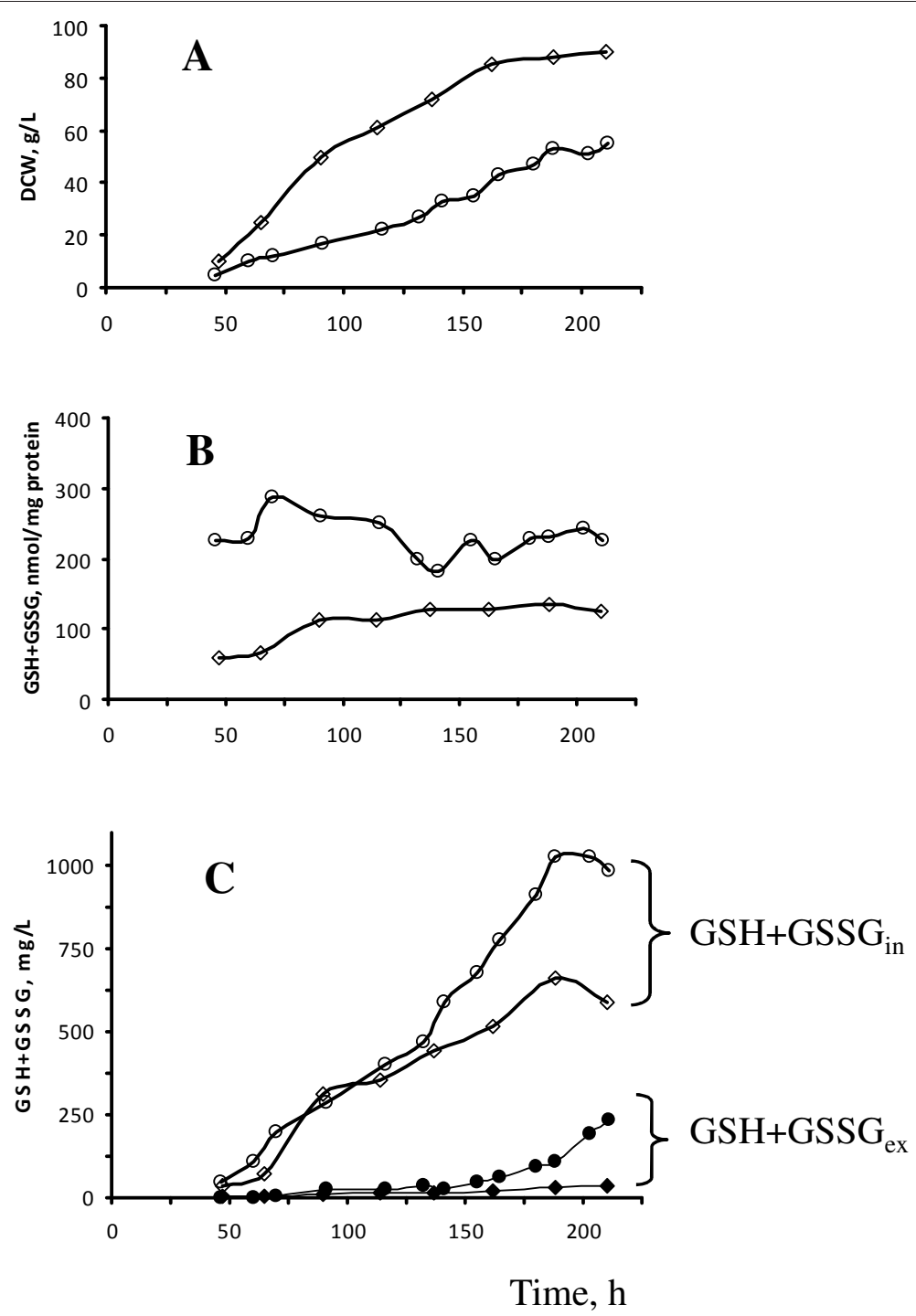

Figure 6 Growth and glutathione accumulation of H. polymorpha DL-1 recombinant strain at methanol-feeding fermenter cultivation. A - Dry cell weight (DCW); B, C - TIG (GSH+GSSG in ) and TEG (GSH+GSSG $)$ concentrations, expressed in nmol/mg protein (B) and in mg/L culture medium (C) of H. polymorpha DL-1 wild type (rhombus) and recombinant strain MOXp-GSH2 (cycle) at fed-batch cultivation in methanol minimal medium under condition of DO-stat $60 \%$. TEG concentration is indicated with filled symbols (C). Values shown are the means of two independent determinations. 
displayed retarded growth in methanol as the sole carbon source as compared to the wild-type strain (Figure 6A). During growth in methanol fed-batch culture, $M O X p-G S H 2$ recombinant strain accumulated about 22.5 fold more TIG (expressed in $\mathrm{nmol} / \mathrm{mg}$ protein) than the parental strain (Figure 6B; Table 2). The concentration of TIG (expressed in $\mathrm{mg} / \mathrm{L}$ ) in this transformant two-fold exceeded that produced by the wild-type strain only in the last period of cultivation (Figure $6 \mathrm{C}$ ). The level of TEG in MOXp-GSH2 transformant grown in methanol was found to be the highest $(250 \mathrm{mg} / \mathrm{L})$ among all tested strains and conditions (Table 2), though it was significantly elevated only at the late fermentation period (Figure 6C).

Reduced ability of $M O X p-G S H 2$ recombinant strain to grow in methanol medium could be caused by inhibition of key enzyme of formaldehyde assimilation, dihydroxyacetone synthetase, by excess of GSH [35] or partial impairment of $M O X$ gene expression as the result of $M O X p-G S H 2$ expression vector integration into the chromosomal MOX locus [36].

So, high-cell-density cultivation of $H$. polymorpha DL-1 wild type strain led to accumulation of large amount of glutathione under dual control of substrate feeding (exponential feeding rate mode combined with feedback control of substrate feed by DO set point using on-off regime). Glucose feeding controlled by DOstat $30 \%$ was found to promote the biomass and TIG concentration of the wild-type strain to $72 \mathrm{~g} / \mathrm{L}$ and 910 $\mathrm{mg} / \mathrm{L}$, respectively (against concentration of biomass and TIG of $44 \mathrm{~g} / \mathrm{L}$ and $518 \mathrm{mg} / \mathrm{L}$, respectively, revealed at DO-stat 60\%). Using the methanol feeding control by DO-stat $60 \%$, the biomass and TIG levels of the wildtype strain reached $90 \mathrm{~g} / \mathrm{L}$ and $676 \mathrm{mg} / \mathrm{L}$, respectively. Genetic engineering of sulfur metabolism and glutathione biosynthetic pathway improved the productivity of glutathione synthesis in $H$. polymorpha recombinant strains 1.3-2.5 times. TIG, TEG and biomass concentrations of the best glutathione-producing recombinant strain, $M O X p-G S H 2$, under methanol fed-batch cultivation comprised $1053 \mathrm{mg} / \mathrm{L}, 250 \mathrm{mg} / \mathrm{L}$ and $55 \mathrm{~g} / \mathrm{L}$, respectively, and at glucose feeding process these parameters were $2257 \mathrm{mg} / \mathrm{L}, 13 \mathrm{mg} / \mathrm{L}$ and $72 \mathrm{~g} / \mathrm{L}$.

One of the best published results on GSH and biomass level for high-GSH-accumulated strain of $S$. cerevisiae G-14 was reported to be $1620 \mathrm{mg} / \mathrm{L}$ and $140 \mathrm{~g} /$ $\mathrm{L}$, respectively, after $52 \mathrm{~h}$ of high-cell-density cultivation with control of glucose feeding by respiratory quotient and ethanol concentration. Optimized process for this strain with addition of amino acids resulted in the glutathione concentration elevation to $2020 \mathrm{mg} / \mathrm{L}$ [27]. Genetically modified strains of the methylotrophic yeast $H$. polymorpha DL-1 studied in the present work, appeared to be competitive glutathione producer with good perspectives for further improvement.

To develop the process of glutathione production based on described here $H$. polymorpha producers, we plan to further optimize growth conditions to increase biomass concentration. Other approach we plan to use will be based on engineering GCS protein for impairment of feedback inhibition normally exerted by glutathione. GCS feedback inhibition engineering will be carried out on the isolated in our laboratory $H$. polymorpha mutants defective both in glutathione uptake and secretory pathways which we found to possess elevated glutathione pool (V. Ubiyvovk et al., unpublished data). It is known that $S$. cerevisiae mutants defective in glutathione transport and in secretory pathways overaccumulate glutathione in the medium [37].

\section{Conclusions}

This study has estimated biothechnological potential of the methylotrophic yeast $H$. polymorpha to produce antioxidant glutathione used as medicine, food additives and in cosmetic industry. Our data showed that recombinant strains of $H$. polymorpha with genetically engineered pathway of global sulfur and glutathione metabolism accumulated the highest to our knowledge titre of intracellular and extracellular glutathione under optimized conditions. We consider $H$. polymorpha as the yeast with good perspectives for further improvement especially for production of extracellular form of glutathione.

\section{Methods}

\section{Microorganisms and cultivation}

Strains of the methylotrophic yeast $H$. polymorpha used in this study are listed in Table 1. For shake-flasks and batch cultivation, strains were grown in YNB medium: $0.17 \%(\mathrm{w} / \mathrm{v})$ yeast nitrogen base without amino acids, $0.5 \%(\mathrm{w} / \mathrm{v})\left(\mathrm{NH}_{4}\right)_{2} \mathrm{SO}_{4}, 2 \%(\mathrm{w} / \mathrm{v})$ glucose or $1 \%$ glycerol. For shake-flasks cultivation it was used shaking diameter of $15 \mathrm{~cm}$. For fed-batch fermentations it was used synthetic salt medium (per litre): $\left(\mathrm{NH}_{4}\right)_{2} \mathrm{SO}_{4}-89.0 \mathrm{~g}$, $\mathrm{KH}_{2} \mathrm{PO}_{4}-28.5 \mathrm{~g}, \mathrm{MgSO}_{4} \cdot 7 \mathrm{H}_{2} \mathrm{O}-6.0$ g, trace elements solution - $5 \mathrm{ml}$, biotin - $0.5 \mathrm{mg}$, thiamine hydrochloride - $20 \mathrm{mg}$. Glucose solution of $500 \mathrm{~g} / \mathrm{L}$ and $100 \%$ methanol were used as the feed media. For transformants stabilization it was used YPD medium: $1 \%$ yeast extract, $2 \%$ peptone, $2 \%$ glucose.

\section{Construction of recombinant $H$. polymorpha strains with integrated multicopy plasmids harbouring genes of GSH biosynthesis}

Standard DNA manipulations were performed as described in Sambrook et al. [38]. Shuttle vector pGLG61, which bears LEU2 selectable marker and gives 
tandem integrated and mitotically stable copies near the end of the chromosome, was used [39].

pGLG61-HpGSH2 plasmid bearing $H$. polymorpha GSH2 gene, homologue of $S$. cerevisiae GSH1 gene, was constructed by subcloning of SmaI-HpaI fragment of pG2 plasmid [21] (1623 bp upstream and 2694 bp downstream regions of ATG codon of $H$. polymorpha CBS4732 chromosomal HpGSH2 gene) into NotI digested and blunted pGLG61 vector.

Plasmid with $H p G S H 2$ driven by strong promoter of $H$. polymorpha alcohol oxidase MOX gene, pGLG61HpMOXp::HpGSH2, was constructed by replacement of human serum albumin (HSA) open reading frame (ORF) from pGLG61-pMOX::HSA plasmid, derived from pYHSA12(+) [36] to ORF of HpGSH2 CBS4732 (1792 bp).

Yeast cells of $H$. polymorpha DL-1 leu2 were transformed with appropriate plasmids by electroporation as described earlier [21]. $\mathrm{Leu}^{+}$transformants that acquired plasmids (pGLG61, pGLG61-HpGSH2 or pGLG61HpMOXp::HpGSH2) were isolated and stabilized by multiple (2-3) passage of transformant culture from YPD to YNB media to integrate plasmids into the genome. Copy number of integrated into chromosomal DNA plasmids was estimated with Southern blot analysis. For that total chromosomal DNA was digested with ClaI endonuclease, fractionated on $0.8 \%$ agarose gel, and then capillary transferred onto a nylon membrane (Schleicher a.Schull GmbH, Dassel, Germany). The DNA probes for Southern blot analysis were labelled with digoxigenin (DIG), using DIG-labelling kit (Roche Diagnostics, Mannheim, Germany).

\section{Reverse transcription (RT)-PCR analysis}

For $H p G S H 2$ transcript analysis yeast cells were grown in YNB medium (1\% glucose) till the middle of the logarithmic phase. Pelleted cells of each studied strain were once washed with water, resuspended in YNB medium to OD-1.0 $(600 \mathrm{~nm})$ without any carbon substrate, split into three equal portions and incubated in the flasks at $37^{\circ} \mathrm{C}$ on rotary shaker (200 rpm) during 1 hour. Later to one out of three flasks of cells suspension it was added glucose $(2 \%)$ or methanol $(0.5 \%)$ or was not added anything for the further incubation during 6 hours.

Total RNA was extracted from yeast cells using the Trizol method (Invitrogen Corporation, Carlsbad, California, USA) following the manufacturer's protocol. RNA was quantified using UV spectrophotometry and diluted in RNAse-free water. Single-stranded cDNA was synthesized using MuLV reverse transcriptase (First Strand cDNA Synthesis Kit, Fermentas, Vilnius, Lithuania). Quantitative RT-PCR analysis was carried out using gene-specific primer pairs and cDNA as a template. The following primer pairs were used: Ax21F 5'-ATCCACAGCGCAATACATACG-3'/Ax22R 5'-TTAACCATTG
ACCCAGTTCGG-3' for the 3' fragment of $H$. polymorpha GSH2; AxF19 (5'-AGATTCAGAGCCCCAGAAG-3') and AxR20 (5'-GCAATACCTGGGAACATGG-3') for the 3 ' fragment of $H$. polymorpha ORF of the ACT1 gene. Sequence of the gene $A C T 1$ was taken from the $H$. polymorpha database [14].

\section{Fermentation techniques}

Inoculum culture of $H$. polymorpha was prepared by $24 \mathrm{~h}$ cultivation in shake-flasks in YNB medium supplemented with glucose. All kinds of fermentations were carried out in BioFlo III bench-top fermenter (New Brunswick Scientific Co. Inc., USA) equipped with standard probes $(\mathrm{pH}$, dissolved oxygen tension, $\mathrm{DO}$, and temperature), with 2.5 liters of media (YNB or synthetic salt media) at $37^{\circ} \mathrm{C}$ without $\mathrm{pH}$ control or at $\mathrm{pH} 5.2$ (maintained by addition of $30 \% \mathrm{NH}_{4} \mathrm{OH}$ or $2 \mathrm{M} \mathrm{HCl}$ ) and with aeration $1 \mathrm{vvm}$ and $200-1000 \mathrm{rpm}$ of stirrer speed.

The fermentations were computer controlled and monitored. High cell density cultivation experiments were carried out as fed-batch fermentations using dual control algorithms of carbon source feeding. Dual control algorithms were programmed using AFS-BioCommand control diagrams, a pictorial function-block language. In fed-batch fermentations set point of substrate $(100 \%$ methanol or $50 \%$ glucose) feed rate changed exponentially [33]. This control mode was combined with feedback control of substrate feed by dissolved oxygen tension (so called DO-stats) using on-off regime. In other words, current value of substrate feed rate was equal to exponentially increasing set point of substrate feed rate till the moment when current value of controlling parameter $\left(\mathrm{DO}_{\mathrm{CV}}\right)$ was passed through the DO set point $\left(\mathrm{DO}_{\mathrm{SP}}\right)$. After return $\mathrm{DO}_{\mathrm{CV}}$ to the $\mathrm{DO}_{\mathrm{SP}}$ predetermined exponential feeding control continued operation. Finally fed-batch processes were represented as pulsing feeding with exponentially increased magnitude of pulsation $[34,40]$.

\section{Fed-batch fermentation on glucose}

It has been done two modes of glucose feeding, using DO-set points $30 \%$ and $60 \%$ (DO-stat 30\% and DO-stat $60 \%$ ), both modes were based on dual control algorithm. DO-stat $30 \%$ (mode I) was chosen to create reduced oxygen concentration and DO-stat $60 \%$ (mode II) was realized for maintenance of oxygen saturation condition. Both kinds of fermentations (with mode I or II) were started as simple batch processes on $2 \%$ glucose at $200 \mathrm{rpm}$ or $600 \mathrm{rpm}$ of stirrer speed, respectively. Glucose feeding was started after stoppage of batch culture growth and followed with gradual increase of stirrer speeds: for fed-batch fermentation of mode I - from 200 to $800 \mathrm{rpm}$ during $24 \mathrm{~h}$ and for mode II - from 600 to $800 \mathrm{rpm}$ during $12 \mathrm{~h}$. 
Mode I of fed-batch was applied for cultivation of all tested strains. Mode II of process was used for cultivation of wild type only.

\section{Fed-batch fermentation on methanol}

Methanol feeding was started after short batch phase of growth on $1 \%$ glycerol (duration 15-17 h) in order to accumulate cell biomass sufficient for DO-response to the methanol addition. Methanol feeding was begun only after complete consuming of glycerol which indicated by sharp increasing of DO level. Next $24 \mathrm{~h}$ of cultivation were carried out at gradual increase of stirrer speed from 600 to $1000 \mathrm{rpm}$ to avoid strong oxygen limitation. Dual control of methanol feeding with DOset point $60 \%$ (DO-stat $60 \%$ ) provided permanent biomass growth. At the time when no changes of biomass concentration observed process was terminated.

\section{Analytical methods}

Cell concentration was evaluated optically at $600 \mathrm{~nm}$ using spectrophotometer Ultrospec 2000 (Pharmacia, Sweden), and by dry cell weight (DCW, g/L). Dry cells were prepared by centrifuging $5 \mathrm{ml}$ of the culture medium at $1000 \times \mathrm{g}$ for $5 \mathrm{~min}$, followed by drying at $105^{\circ} \mathrm{C}$ for $4 \mathrm{~h}$. The concentration of glucose in cultivation medium was measured using glucose oxidase method with a glucose assay kit (Sigma-Aldrich Corporation, St. Louis, Missouri, USA).

The total glutathione concentration (GSH+GSSG) was measured in culture medium supernatant and in the cell-free extracts. The lasts were prepared by yeast cells vortexing in Eppendorf microtubes at $4^{\circ} \mathrm{C}$ for $20 \mathrm{~min}$ with $0.1 \mathrm{M}$ potassium-phosphate buffer, $\mathrm{KPB}, \mathrm{pH} 7.5$ and glass beads, $425-600 \mu \mathrm{m}$, in the ratio $1: 1: 1(\mathrm{v} / \mathrm{v} / \mathrm{v})$ followed with centrifugation of the mixture at $4^{\circ} \mathrm{C}$ for $20 \mathrm{~min}$ at $20000 \times \mathrm{g}$. Protein was determined using Bio Rad DC protein assay in microplate reader at $690 \mathrm{~nm}$.

Total Intracellular Glutathione (TIG) GSH+GSSG content was quantified by a modification of the standard recycling assay based on the reduction of 5,5-dithiobis(2-nitrobenzoic acid) (DTNB) in the presence of glutathione reductase and NADPH [41]. Procedure was adapted to 96-well plates: each well contained $140 \mu \mathrm{l}$ of $0.2 \mathrm{mM}$ NADPH, $20 \mu \mathrm{l}$ of glutathione reductase solution, $0.4 \mathrm{U} / \mathrm{ml}$ (both solutions prepared on $0.05 \mathrm{mM}$ $\mathrm{KPB}$ pH 7.5 containing $5 \mathrm{mM}$ EDTA) and $20 \mu \mathrm{l}$ of GSH standard solution $(100,50,25,12.5,6.25,3.125$ and $1.56 \mu \mathrm{M})$ or $20 \mu \mathrm{l}$ sample solution (10-100 times-diluted extracts). Reaction was started with $20 \mu \mathrm{l}$ of $3 \mathrm{mM}$ DTNB (promptly added by multipipetman). Microplate was incubated at room temperature for 10-20 min and the absorbance of each well was read at $405 \mathrm{~nm}$ using microplate reader. Usually (GSH+GSSG) concentration was expressed in nmoles/mg protein in cell-free extracts or in $\mathrm{mg} / \mathrm{L}$ culture medium; cellular (GSH+GSSG) content - in \% of dry cell weight or $\mathrm{mg} / \mathrm{g}$ dry cells.

\section{Abbreviations}

GSH: reduced form of tripeptide glutathione; GSSG: disulfide form of oxidized glutathione; TIG: Total Intracellular Glutathione or GSH+GSSG in TEG: Total Extracellular Glutathione or GSH+GSSG

\section{Acknowledgements}

This research was funded by National Academy of Science of Ukraine and by bilateral Korean-Ukrainian treatment cooperation project between H.A. Kang and A.A. Sibirny. We thank Dr. K.V. Dmytruk for design of transcript analysis experiment and edition of manuscript.

\section{Author details}

${ }^{1}$ Institute of Cell Biology NAS of Ukraine, Drahomanov Street, 14/16, Lviv, 79005 Ukraine. ${ }^{2}$ Korea Research Institute of Bioscience and Biotechnology, Daejeon, 305-333, Korea. ${ }^{3}$ Department of Life Science, Chung-Ang University, Heukseok-dong, Dongjak-gu, Seoul, 156-756, Korea. ${ }^{4}$ University of Rzeszow, Cwiklinskiej 2, Rzeszow 35-601 Poland.

\section{Authors' contributions}

VMU carried out the molecular cloning and glutathione assays, drafted manuscript. VMA carried out microbiological and fermentation experiments and helped to write the manuscript. AYM performed transcript analysis. HAK conceived the study, designed the experiment and helped to write the manuscript. AAS reviewed and edited the paper. All authors read and approved the final manuscript.

Received: 11 August 2010 Accepted: 22 January 2011 Published: 22 January 2011

\section{References}

1. Penninckx MJ: A short review on the role of glutathione in the response of yeasts to nutritional, environmental, and oxidative stresses. Enzyme Microb Technol 2000, 26:737-742.

2. Pócsi I, Prade RA, Penninckx MJ: Glutathione, altruistic metabolite in fungi. Adv Microb Physiol 2004, 49:1-76.

3. Li Y, Wei G, Chen J: Glutathione: a review on biotechnological production. Appl Microbiol Biotechnol 2004, 66:233-242.

4. Bachhawat AK, Ganguli D, Kaur J, Kasturia N, Thakur A, Kaur H, Kumar A, Yadav A: Glutathione Production in Yeast. In Yeast Biotechnology: Diversity and Applications. Volume 259. Edited by: Satyanarayana T, Kunze G. Springer Science + Business Media B.V; 2009, chapter 13.

5. Chatterjee S, de Lamirande E, Gagnon C: Cryopreservation alters membrane sulfhydryl status of bull spermatozoa: protection by oxidized glutathione. Mol Reprod Dev 2001, 60:498-506.

6. Kozhemyakin LA, Balasovski MB: Methods for production of the oxidized glutathione composite with CIS-diamminedichloroplatinum and pharmaceutical compositions based thereof regulating metabolism, proliferation, differentiation and apoptotic mechanisms for normal and transformed cells. US patent 7,371,411 2008.

7. In Hansenula polymorpha. Biology and Application. Edited by: Gellissen G. Weinheim: Wiley-VCH Verlag GmbH; 2002.

8. In Production of Recombinant Proteins. Novel Microbial and Eukaryotic Expression Systems. Edited by: Gellissen G. Weinheim: Wiley-VCH Verlag GmbH; 2005.

9. Ishchuk OP, Voronovsky AY, Abbas CA, Sibirny AA: Construction of Hansenula polymorpha strains with improved thermotolerance. Biotechnol Bioeng 2009, 104:911-919.

10. Voronovsky AY, Rohulya OV, Abbas CA, Sibirny AA: Development of strains of the thermotolerant yeast Hansenula polymorpha capable of alcoholic fermentation of starch and xylan. Metab Eng 2009, 11:234-242.

11. Ishchuk OP, Voronovsky AY, Stasyk OV, Gayda GZ, Gonchar MV Abbas CA, Sibirny AA: Overexpression of pyruvate decarboxylase in the yeast Hansenula polymorpha results in increased ethanol yield in high-temperature fermentation of xylose. FEMS Yeast Res 2008, 8:1164-1174.

12. Dmytruk OV, Dmytruk KV, Abbas CA, Voronovsky AY, Sibirny AA: Engineering of xylose reductase and overexpression of xylitol dehydrogenase and 
xylulokinase improves xylose alcoholic fermentation in the thermotolerant yeast Hansenula polymorpha. Microb Cell Fact 2008, 7:21.

13. Ramezani-Rad M, Hollenberg CP, Lauber J, Wedler H, Griess E, Wagner C, Albermann K, Hani J, Piontek M, Dahlems U, Gellissen G: The Hansenula polymorpha (strain CBS4732) genome sequencing and analysis. FEMS Yeast Res 2003, 4:207-215.

14. Hansenula polymorpha Genome Database [http://genome.jgi-psforg/ Hanpo1/Hanpo1.home.html].

15. Kim YH, Han KY, Lee K, Heo JH, Kang HA, Lee J: Comparative proteome analysis of Hansenula polymorpha DL1and A16. Proteomics 2004, 4:2005-2013.

16. Oh KS, Kwon O, Oh YW, Sohn MJ, Jung S, Kim YK, Kim MG, Rhee SK, Gellissen G, Kang HA: Fabrication of a partial genome microarray of the methylotrophic yeast Hansenula polymorpha: optimization and evaluation for transcript profiling. J Microbiol Biotechnol 2004, 14:1239-1248.

17. Sahm H: Metabolism of methanol by yeast. Adv Biochem Eng 1977, 6:77-103.

18. Sibirny AA, Ubiyvovk VM, Gonchar MV, Titorenko VI, Voronovsky AY, Kapultsevich YG, Bliznik KM: Reaction of direct formaldehyde oxidation to $\mathrm{CO}_{2}$ are non-essential for energy supply of yeast methylotrophic growth. Arch Microbiol 1990, 154:566-575.

19. Horiguchi H, Yurimoto H, Kato N, Sakai Y: Antioxidant system within yeast peroxisome-Biochemical and physiological characterization of CbPmp20 in the methylotrophic yeast Candida boidinii. J Biol Chem 2001, 276:14279-14288.

20. Ubiyvovk VM, Telegus $\mathrm{YV}$, Sibirny AA: Isolation and characterization of glutathione-deficient mutants of the methylotrophic yeast Hansenula polymorpha. In Microbiology. Volume 68. Moscow; 1999:26-31.

21. Ubiyvovk VM, Nazarko TY, Stasyk OG, Sohn MJ, Kang HA, Sibirny AA: GSH2, a Gene Encoding gamma-Glutamylcysteine Synthetase in the Methylotrophic Yeast Hansenula polymorpha. FEMS Yeast Research 2002, 2:327-332.

22. Ubiyvovk VM, Maszewski J, Bartosz G, Sibirny AA: Vacuolar accumulation and extracellular extrusion of electrophilic compounds by the cells of wild type strain and glutathione deficient mutants of the methylotrophic yeast Hansenula polymorpha. Cell Biology Int 2003, 27:785-789.

23. Ubiyvovk VM, Blazhenko OV, Gigot D, Penninckx M, Sibirny AA: Role of gamma-glutamyltranspeptidase in detoxification of xenobiotics in the yeasts Hansenula polymorpha and Saccharomyces cerevisiae. Cell Biology International 2006, 30:665-671.

24. Sohn MJ, Ubiyvovk VM, Oh DB, Kwon O, Lee SY, Kang HA: Transcriptome analysis of Met4p-mediated sulfur regulatory circuit in the methylotrophic yeast Hansenula polymorpha. In Proceedings of the Intern. Specialised Symp. On Yeasts ISSY25, Systems Biology of Yeasts-from Models to Applications: 18-21 June 2006; Hanasaari, Espoo, Finland. Edited by: Kuokka A, Penttila M. Organised by VIT, Finland; 2006:P105.

25. Thomas D, Jacquemin I, Surdin-Kerjan Y: MET4, a leucine zipper protein, and centromere-binding factor 1 are both required for transcriptional activation of sulfur metabolism in Saccharomyces cerevisiae. Mol Cell Biol 1992, 12:1719-1727.

26. Blazhenko OV, Zimmermann M, Kang HA, Bartosz G, Penninckx M, Ubiyvovk VM, Sibirny AA: Accumulation of cadmium ions in the methylotrophic yeast Hansenula polymorpha. BioMetals 2006, 19:593-599.

27. Wang Z, Tan T, Song J: Effect of amino acids addition and feedback control strategies on the high-cell-density cultivation of Saccharomyces cerevisiae for glutathione production. Process Biochemistry 2007, 42:108-111.

28. Lahtchev KL, Semenova VD, Tolstorukov $\cdot \| l$, van der Klei I, Veenhuis M: Isolation and properties of genetically defined strains of the methylotrophic yeast Hansenula polymorpha CBS4732. Arch Microbiol 2002, 177:150-158.

29. Gasch AP, Werner-Washburne M: The genomics of yeast responses to environmental stress and starvation. Funct Integr Genomics 2002, 2:181-192.

30. Klatt $P$, Lamas $S$ : Regulation of protein function by S-glutathiolation in response to oxidative and nitrosative stress. Eur J Biochem 2000, 267:4928-4944.
31. Esterbauer $\mathrm{H}, \mathrm{Schaur} \mathrm{RJ}$, Zollner $\mathrm{H}$ : Chemistry and biochemistry of 4hydroxynonenal, malondialdehyde and related aldehydes. Free Radic Biol Med 1991, 11:81-128.

32. Hartner FS, Glieder A: Regulation of methanol utilisation pathway genes in yeasts. Microbial Cell Factories 2006, 5:39-60.

33. Ananin VM, Baev AV, Vel'kov W: Controlled Cultivation of Methylotrophic Yeast Hansenula polymorpha. Applied Biochemistry and Microbiology 1997, 33:74-77.

34. Park BS, Ananin V, Kim CH, Rhee SK, Kang HA: Secretory production of Zymomonas mobilis levansucrase by methylotrophic yeast Hansenula polymorpha. Enzyme and Microbial Technology 2004, 34:132-138.

35. Bystrykh LV, Sokolov AP, Trotsenko YA: Purification and properties of dihydroxyacetone synthase from the methylotrophic yeast Candida boidinii. FEBS Lett 1981, 132:324-328.

36. Kang HA, Kang W, Hong WK, Kim MW, Kim JY, Sohn JH, Choi ES, Choe KB, Sang KR: Development of Expression Systems for the Production of Recombinant Human Serum Albumin Using the MOX Promoter in Hansenula polymorpha DL-1. Biotechnology and Bioengineering 2001, 76:175-185.

37. Perrone GG, Grant CM, Dawes IW: Genetic and Environmental factors influencing glutathione homeostasis in Saccharomyces cerevisiae. Mol Biol Cell 2005, 16:218-230.

38. Sambrook J, Fritsch EF, Maniatis T: Molecular cloning: a laboratory manual. 2 edition. Cold Spring Harbor, NY: Cold Spring Harbor Press; 1989.

39. Sohn JH, Choi ES, Kang HA, Rhee JS, Agaphonov MO, Ter-Avanesyan MD, Rhee SK: A dominant selection system designed for copy-numbercontrolled gene integration in Hansenula polymorpha DL-1. Appl Microbiol Biotechnol 1999, 51:800-807.

40. Yee L, Blanch HW: Recombinant Protein Expression in High Cell Density Fed-Batch Cultures of Escherichia coli (Review). Biotechnology 1992, 10:1550-1555.

41. Brehe J, Burch HB: Enzymatic assay of glutathione. Anal Biochem 1976, 74:189-197.

doi:10.1186/1472-6750-11-8

Cite this article as: Ubiyvovk et al:: Optimization of glutathione production in batch and fed-batch cultures by the wild-type and recombinant strains of the methylotrophic yeast Hansenula polymorpha DL-1. BMC Biotechnology 2011 11:8.

\section{Submit your next manuscript to BioMed Central and take full advantage of:}

- Convenient online submission

- Thorough peer review

- No space constraints or color figure charges

- Immediate publication on acceptance

- Inclusion in PubMed, CAS, Scopus and Google Scholar

- Research which is freely available for redistribution

Submit your manuscript at www.biomedcentral.com/submit
Ciomed Central 